\title{
Influence of the geometry of nanostructured hydroxyapatite and alginate composites in the initial phase of bone repair ${ }^{1}$
}

George Gonçalves dos Santos' (i), Luisa Queiroz Vasconcelos", Suelen Cristina da Silva Poy'I', Renata dos Santos Almeida'v (i), Aryon de Almeida Barbosa Júniorv, Silvia Rachel de Albuquerque Santos ${ }^{\mathrm{VI}}$, Alexandre Malta Rossi ${ }^{\mathrm{VII}}$, Fúlvio Borges Miguel ${ }^{\mathrm{VIII}}$, Fabiana Paim Rosa ${ }^{\mathrm{IX}}$

'Master, Fellow PhD degree, Postgraduate Program in Interactive Processes of Organs and Systems, Health Sciences Institute, Universidade Federal da Bahia (UFBA), Salvador-BA, Brazil. Technical procedures, manuscript writing.

"Master, Fellow PhD degree, Postgraduate Program in Interactive Processes of Organs and Systems, Health Sciences Institute, UFBA, Salvador-BA, Brazil. Technical procedures.

"'Master, Faculdade Maria Milza (FAMAM), Mangabeira-BA, Brazil. Technical procedures, histological examinations.

IVPD, Postgraduate Program in Interactive Processes of Organs and Systems, Health Sciences Institute, UFBA, Salvador$\mathrm{BA}$, Brazil. Histomorphometric examinations.

${ }^{\mathrm{V}} \mathrm{PhD}$, Researcher Collaborator, Laboratory of Tissue Bioengineering and Biomaterials (LBTB), Health Sciences Institute, UFBA, Salvador-BA, Brazil. Histopathological examinations.

${ }^{V I}$ Chemistry, LABIOMAT, Brazilian Center for Physics Research, CBPF, Rio de Janeiro-RJ, Brazil. Analysis, synthesis and physicochemical characterization of biomaterials.

VIIPhD, LABIOMAT, Brazilian Center for Physics Research, CBPF, Rio de Janeiro-RJ, Brazil. Analysis, synthesis and physicochemical characterization of biomaterials.

VIIIPhD, Associate Professor, Health Sciences Center, Universidade Federal do Recôncavo da Bahia (UFRB), Santo Antonio de Jesus-BA, Brazil. Technical procedures, critical revision.

'XPhD, Associate Professor, Health Sciences Institute, UFBA, Salvador-BA, Brazil. Conception of the study, critical revision.

\section{Abstract}

Purpose: To analyze, histomorphologically, the influence of the geometry of nanostructured hydroxyapatite and alginate (HAn/Alg) composites in the initial phase of the bone repair.

Methods: Fifteen rats were distributed to three groups: MiHA - bone defect filled with HAn/Alg microspheres; GrHA - bone defect filled with HAn/Alg granules; and DV - empty bone defect; evaluated after 15 days postoperatively. The experimental surgical model was the critical bone defect, $\cong 8.5 \mathrm{~mm}$, in rat calvaria. After euthanasia the specimens were embedded in paraffin and stained with hematoxylin and eosin, picrosirius and Masson-Goldner's trichrome.

Results: The histomorphologic analysis showed, in the MiHA, deposition of osteoid matrix within some microspheres and circumjacent to the others, near the bone edges. In GrHA, the deposition of this matrix was scarce inside and adjacent to the granules. In these two groups, chronic granulomatous inflammation was noted, more evident in GrHA. In the DV, it was observed bone neoformation restricted to the bone edges and formation of connective tissue with reduced thickness in relation to the bone edges, throughout the defect.

Conclusion: The geometry of the biomaterials was determinant in the tissue response, since the microspheres showed more favorable to the bone regeneration in relation to the granules.

Key words: Durapatite. Alginates. Polymers. Microspheres. Rats. 


\section{Introduction}

Researchers of the bone tissue bioengineering have sought to develop ideal conditions for the repair and/or replacement of damaged or lost tissue through the use of cellular elements, growth factors, regenerative techniques and biomaterials, in order to provide the scaffold and essential requirements for tissue neoformation ${ }^{1-3}$.

The biomaterials can be synthesized from different substrates and processed in different forms of presentation, namely: fiber, membrane, gel, powder, among others; and different geometries such as plates, cylinders, microspheres and granules. Microspheres have attracted great scientific interest due, in particular, to their ability to promote the formation of interstices between them, which allows cell migration, adhesion, proliferation and differentiation, mainly, mesenchymal and osteoprogenitoring, liberation of growth factors, angiogenesis, diffusion of nutrients and new extracellular matrix (ECM) synthesis ${ }^{4}$. By turn the granules, in addition to having the aforementioned properties, are widely used in clinical practice in the filling of defects and tissue lesions with irregular shapes. Both microspheres and granules can be applied through injectable systems in minimally invasive surgical procedures ${ }^{5}$.

Among the substrates most used in the synthesis of biomaterials with the geometry of microspheres and granules, bioceramics based on calcium phosphate (CaP) stand out, mainly, the HA due to its biocompatibility, osteoconduction and bioactivity ${ }^{6}$. However, in spite of these fundamental properties, in the biological interaction with the host, the HA presents a low in vivo degradation rate which, in some applications, may limit its use ${ }^{7}$.

In seeking to improve the physicochemical characteristics of HA, researchers have developed this material on a nanometer scale, considering that the HA nanostructured crystals (HAn) have higher biodegradation due to the smaller size of its particles and larger surface area exposed to the biological environment, which accelerates the speed of formation and growth of the biologically active apatite layer ${ }^{7,8}$. Another way to improve bioceramics is to associate them with natural or synthetic polymers to produce biomaterials of the type composites ${ }^{2,9}$. These materials have, in the same scaffold, physicalchemical properties of the ceramic and polymer, which are improved in relation to the materials when used in an individual way and mimetize the inorganic and organic phases of the natural bone ${ }^{10-12}$.

In this perspective, the alginate is a natural polymer widely used, since this material can alter the crystallinity, solubility, network parameters, thermal stability, surface reactivity, bioactivity and adsorption properties of the HA structure ${ }^{9,13,14}$. Therefore, the physicochemical characteristics of the composites vary according to the polymer and its percentage used during the synthesis, as well as the processing of the sample and the final geometry of the biomaterial produced. Thus, these biomaterials, especially in the form of microspheres and granules are configured as a promising alternative to bone substitution, particularly in situations where damage and/ or trauma reach critical dimensions which preclude spontaneous bone regeneration and hinders the functional property or aesthetic of the affected $^{15,16}$.

Given the above, parallel to the need, in worldwide level, to develop new biomaterials, with national technology and affordable cost, most versatile, and promising biological properties for use, especially in cases of extensive bone loss, the present study aims to analyze the influence of the geometry of HAn 
and alginate composites in the initial phase of bone repair.

\section{- Methods}

Surgical procedures were performed according to the Ethical Standards of Researches in Animals (Law No. 11,794 of 2008); the National Biosafety Standards and the National Health Institute Guidelines for the Care and Use of Laboratory Animals (NIH Publication No. 85-23, Rev. 1985), upon approval of the Ethics Committee on the Use of Animals of the Health Sciences Institute, Universidade Federal da Bahia, protocol 038/2012.

\section{Biomaterials}

Synthesis and processing of the HAn and alginate microspheres and granules

The biomaterials were synthesized, processed and characterized in the LABIOMAT (Brazilian Center for Physical Research, CBPF, Rio de Janeiro, Brazil). The synthesis was realized by mixing a solution of ammonium hydrogenphosphate $\left[\left(\mathrm{NH}_{4}\right)_{2} \mathrm{HPO}_{4}\right]$, maintained at $\mathrm{pH} \mathrm{11}$, to a solution of calcium nitrate tetrahydrate $\left[\mathrm{Ca}\left(\mathrm{NO}_{3}\right)_{2} \cdot 4 \mathrm{H}_{2} \mathrm{O}\right]$ under constant stirring, under synthesis temperature of $90^{\circ} \mathrm{C}$.

The precipitate resulting was filtered and washed until the $\mathrm{pH}$ of the wash water was 7. Soon after, the solid obtained was dried by freeze-drying for $24 \mathrm{~h}$ and then separated using sieves with a desired mesh aperture. $15 \mathrm{~g}$ of the obtained solid were weighed into becker and added to a $1.5 \% \mathrm{w} / \mathrm{v}$ solution of sodium alginate, vigorously mixed until obtain a homogeneous paste.

To obtain the microspheres, this paste was extruded with the use of a syringe in $0.15 \mathrm{M}$ calcium chloride solution at room temperature. Finally, the microspheres were washed and dried in a glass-house at 50응
$C$ and then submitted to the sieve with a granulometric range of 250-425 $\mu \mathrm{m}$. In order to obtain the granules, the obtained paste was dried in a glass-house and then crushed and sieved in the granulometric range of 250-425 $\mu \mathrm{m}$. The biomaterial samples were conditioned in eppendorf tubes, properly identified, and sterilized by gamma rays (Fig. 1). Each aliquot was used to fill the bone defect of, approximately, four animals.

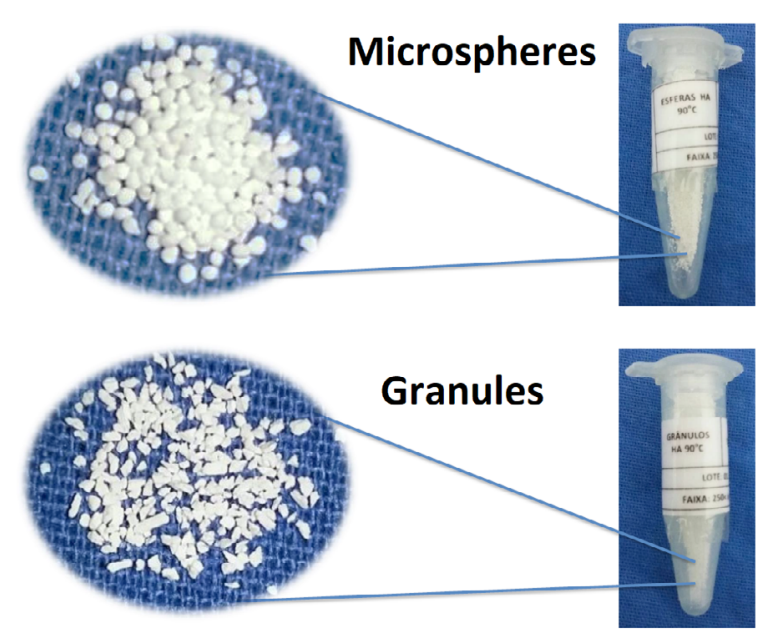

Figure 1 - Macroscopic aspect of biomaterials.

\section{Physical-chemical characterization of HAn powders}

\section{Superficial area}

The characterization of the surface area by the BET method (ASAP 2020-Micromeritics ${ }^{\circ}$ ) showed that the HA evaluated in our study has a surface area of $35.9501 \mathrm{~m}^{2} / \mathrm{g}$, characteristic of manometric biomaterials.

Chemical analysis

The chemical analysis of the X-ray fluorescence (XRF) (PW2400-Philips ${ }^{\circ}$ ) demonstrated that $\mathrm{HA}$ evaluated in this work presents Ca/P molar ratio of 1.67 (Table 1). 
Table 1 - XRF analysis.

\begin{tabular}{cccccc}
\hline Sample & Ca \% & mol do Ca & P \% & mol do P & Ratio Ca/P \\
\hline HA & 35.70 & 0.8908 & 16.40 & 0.52948 & 1.6823 \\
HA & 36.00 & 0.8982 & 16.60 & 0.53593 & 1.6760 \\
HA & 37.12 & 0.9262 & 17.20 & 0.55530 & 1.6679 \\
& & & & Mean & $\mathbf{1 . 6 7 5 4}$ \\
\hline
\end{tabular}

$\mathrm{Ca} \%=$ Percent of Calcium. mol of $\mathrm{Ca}=$ Calcium Concentration. $\mathrm{P} \%=$ Percent of Phosphate. $\mathrm{mol}$ of $\mathrm{P}=$ Phosphate Concentration. Ratio $\mathrm{Ca} / \mathrm{P}=$ ratio of calcium and phosphate.

$\underline{X}$-ray diffraction (X-RD) analysis

The analysis of X-ray diffraction was performed using the high-resolution diffractometer HZG4 (Zeiss ${ }^{\circ}$ ) with CuKa radiation ( $I=1.5418 \AA)$ and angular scanning of 10 $80^{\circ}(2 \theta)$, with step of $0.05 / \mathrm{s}$, time 160 seconds, with reference to the standard PCPDFWIN 09.0432 (International Centre for Diffraction Data - ICDD $)^{17,18}$. The diffractogram evidenced peaks corresponding to the crystalline profile of a standard HA (Fig. 2).

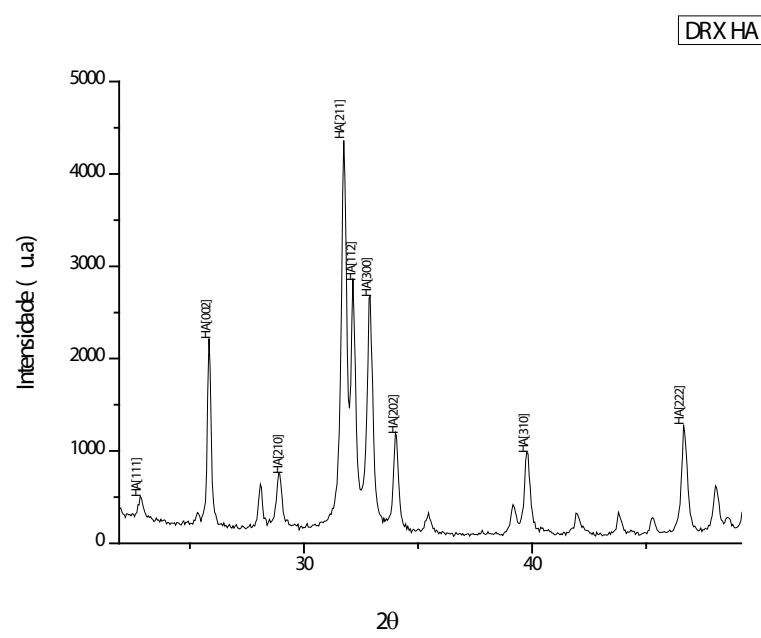

Figure 2 - Peaks corresponding to the crystallinity of a standard HA are noted.

Fourier Transform Infrared Spectroscopy (FTIR)

The FTIR analysis evidenced vibrational spectra corresponding to those of a standard $\mathrm{HA}^{17,18}$, it is noted in the regions of 3430 and $1646 \mathrm{~cm}^{-1}$ intense and wide water bands. In the regions 1462 to $1414 \mathrm{~cm}^{-1}$ are found the characteristic bands of the carbonate ions, showing that the alginate is present in the sample. The other bands observed in 1038, 961,602 and $560 \mathrm{~cm}^{-1}$ are characteristic of phosphate ions present in HA. Even the sample containing a large amount of water, it was possible to identify the hydroxyl bands in 3570 and $635 \mathrm{~cm}^{-1}$ (Fig. 3).

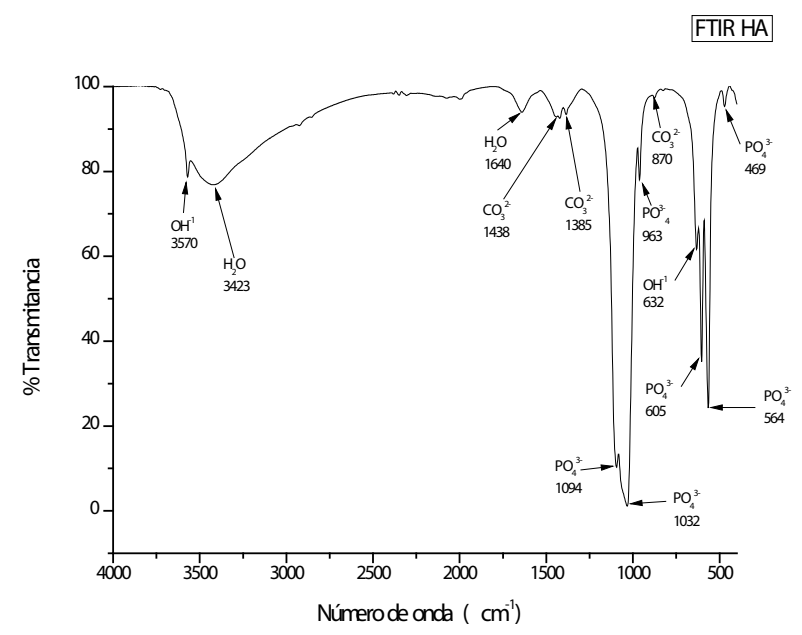

Figure 3 - Vibrational spectra of Infrared of the sample prepared at $90^{\circ} \mathrm{C}$. It is observed that the spectra revealed characteristic bands of $\mathrm{HA}$ for phosphate $\left(\mathrm{PO}_{4}{ }^{3-}\right)$, water $\left(\mathrm{H}_{2} \mathrm{O}\right)$ and hydroxyl $\left(\mathrm{OH}^{1-}\right)$.

\section{Experimental phase}

Fifteen male wistar albino adult rats with body weight between 350 and $400 \mathrm{~g}$ were randomly distributed to compose three experimental groups, with 5 animals in each group: MiHA - bone defect filled with HAn microspheres and alginate; GrHA - bone 
defect filled with HAn granules and alginate; DV - bone defect without implantation of biomaterial.

\section{Surgical procedure}

The surgical technique used was the same described by Miguel et al. ${ }^{19}$. However, in the present study, the $8.0 \mathrm{~mm}$ trephine drill used in the confection of the critical bone defect was with a diameter of $\cong 8.5 \mathrm{~mm}$ and $\cong 0.8 \mathrm{~mm}$ of thickness. After removal of the bone fragment, it was procedered the implantation of the biomaterials, according to each experimental group. In the control group (DV) the bone defect remained empty, without biomaterial. Finally, the tissue flap was repositioned and sutured with simple points (Fig. 4).
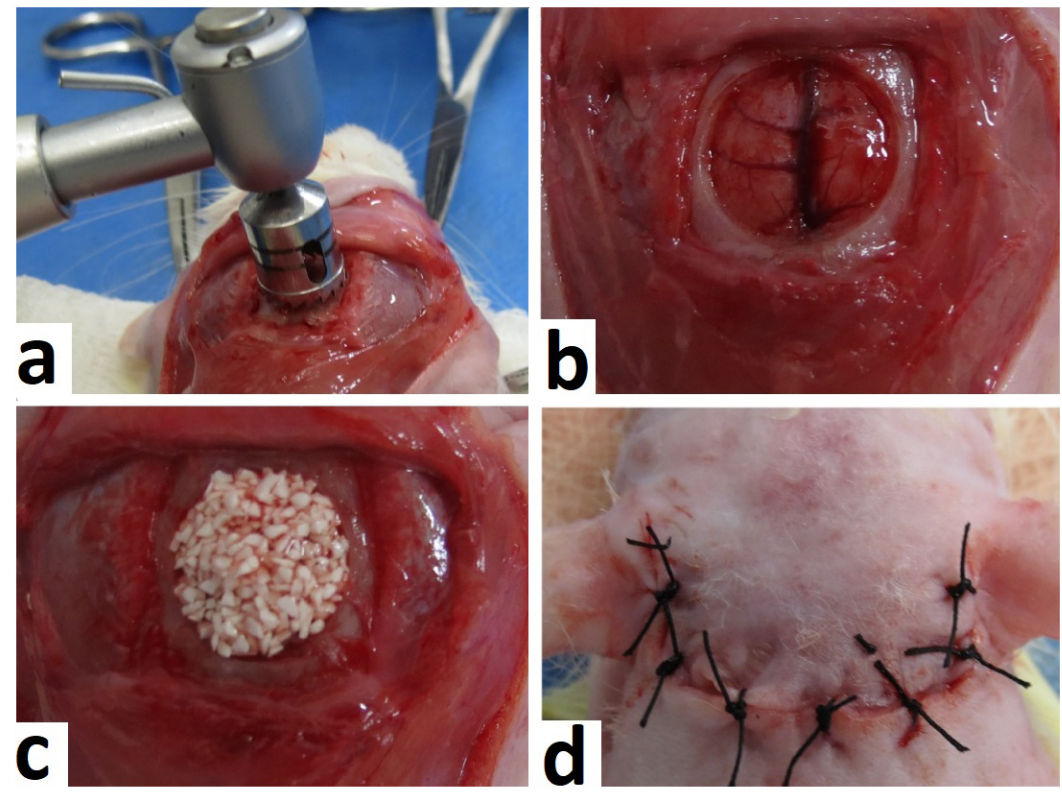

Figure 4 - Steps of the surgical procedure. a) Removal of the bone fragment with trephine drill. b) Critical bone defect. c) Implanted Biomaterial. d) Tissue flap repositioned and sutured.

\section{Histological processing and}

histomorphological analysis

After 15 days post surgery, the animals were euthanized and the calvaria removed. The obtained specimens were fixed formaldehyde $4 \%$ for 48 hours, included in paraffin and subsequently cut to $5 \mu \mathrm{m}$ of thickness and stained with hematoxylin-eosin (HE), picrosirius-red (PIFG) and MassonGoldner trichrome (GOLD) and analyzed under an optical microscope (DM1000 - Leica ${ }^{\circ}$ ). The images were captured using a digital camera (DFC310FX - Leica ${ }^{\circ}$ ). For morphometric analyses, the Leica Application Suite (version 4.12 - Leica $^{\circ}$ ) and optical microscope (DM6 B Leica $^{\circ}$ ) were used. To compare the differences between the groups the Kruskal-Wallis test was applied using the software SPSS version $20.0\left(I B M S P S S^{\circ}\right)$, at a $5 \%$ level of significance $(p \leq 0.05)$.

\section{- Results}

The histomorphologic analysis evidenced neoformation of osteoid matrix restricted to the borders of the bone defect with formation of fibrous connective tissue 
in the remaining area, in all experimental groups. When compared to the bone edge, the tissue thickness produced in the defect region remained proportional in the groups with implantation of microspheres and granules, and significantly reduced in the group without implantation of biomaterials (Fig. 5).

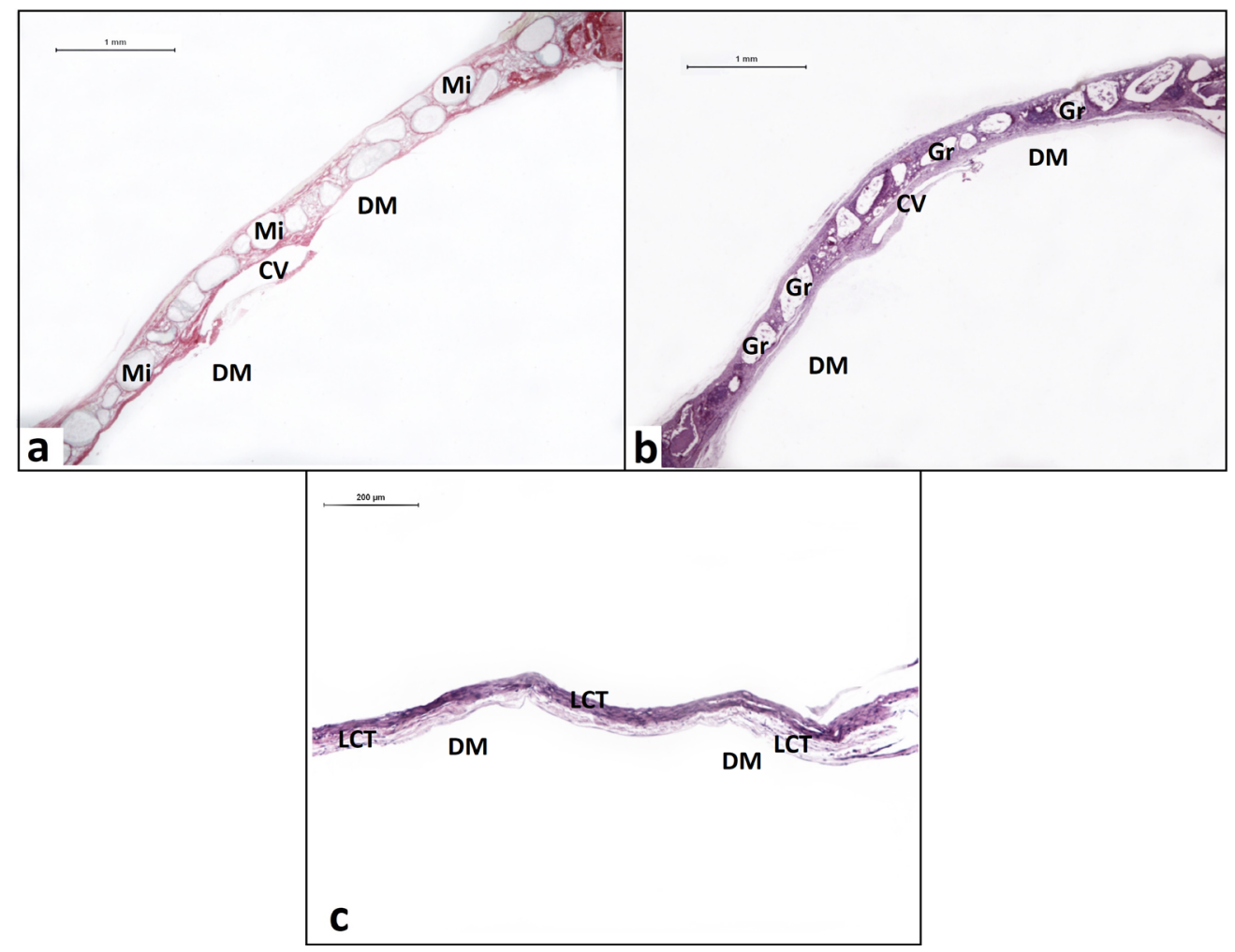

Figure 5 - a) MiHA - Microspheres distributed along the bone defect. PIFG. Bar: $1 \mathrm{~mm}$. b) GrHA - Granules arranged along the bone defect. HE. $1 \mathrm{~mm}$ bar. c) DV - Deposition of conjunctive tissue throughout the bone defect. HE. Bar: $200 \mu \mathrm{m}$. Microspheres (Mi), granules (Gr), loose connective tissue (LCT), central vein (CV) and dura mater region (DM).

In the MiHA, the biomaterials were arranged in monolayer, with small variation of microspheres size, throughout the extent of the bone defect. The majority remained intact and some presented partial and/or total fragmentation with neoformation of osteoid matrix within the scaffold. In this group, it was observed the presence of mononuclear inflammatory cells and multinucleated giant cells, characteristic of chronic granulomatous inflammatory response, discreetly noticed around the microspheres, especially those located at the periphery of the bone defect.
In GrHA, the granules were distributed in mono and multilayer, throughout the extent of the bone defect. In this group the chronic granulomatous inflammatory reaction observed was more evident than in the MiHA. Most of the granules remained intact, while others presented partial fragmentation, less accentuated in relation to the microspheres, without osteoid neoformation inside of the biomaterials. In both groups with implantation of biomaterials, it was noticed abundant proliferation of blood capillaries around the particles (Fig. 6). 


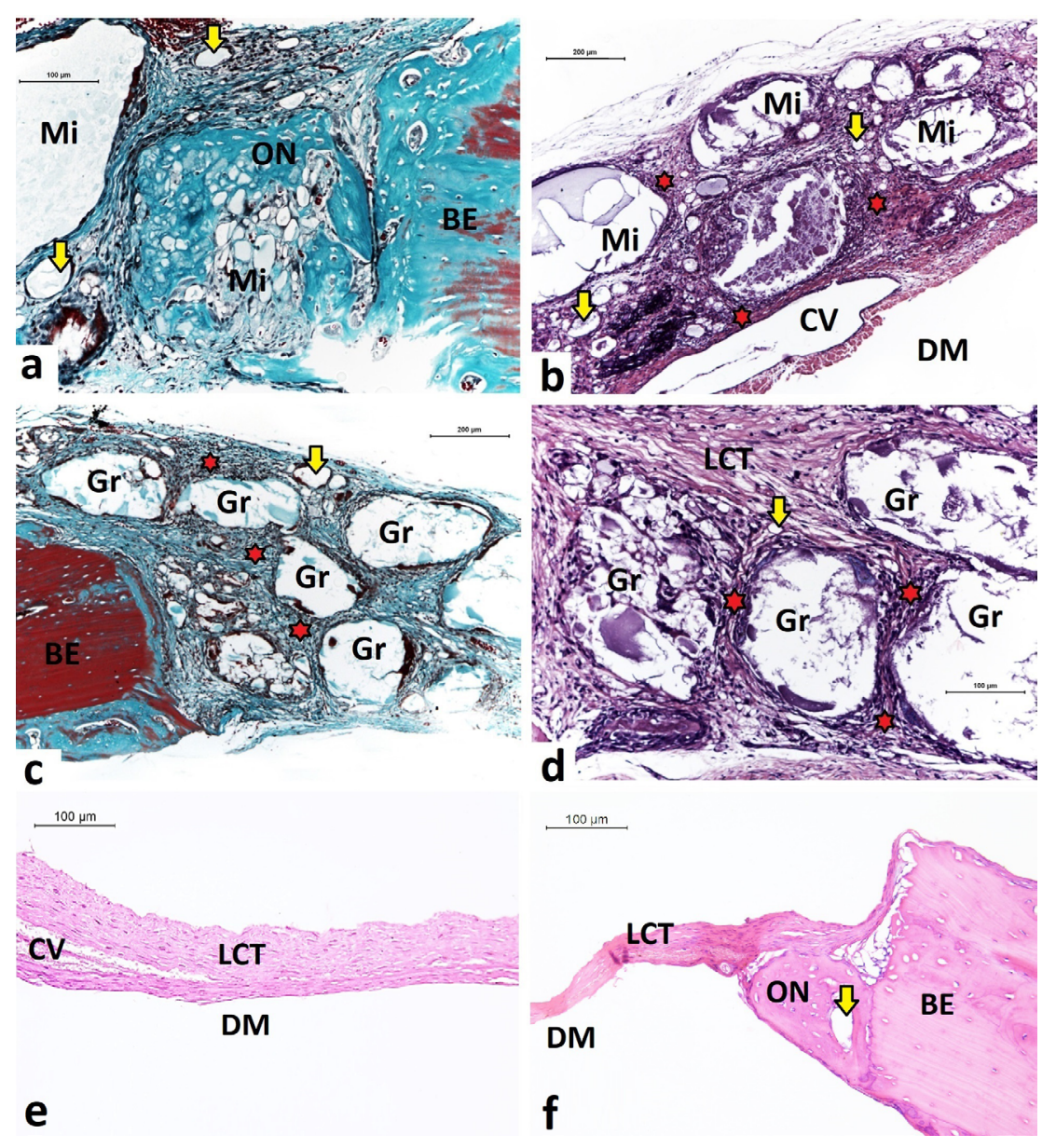

Figure 6 - a) MiHA - Neoformation osteoid within the microsphere and discrete circumferential chronic granulomatous inflammation. GOLD. Bar: $100 \mu \mathrm{m}$. b) MiHA - Microspheres partially degraded and tissue neoformation within the particles. HE. Bar: $200 \mu \mathrm{m}$. c) GrHA - integrity of granules and scarce neoformation osteoid restricted to the bone edges. GOLD. Bar: $200 \mu \mathrm{m}$. d) GrHA - Intense chronic granulomatous inflammation surrounding the granules. HE. Bar: $100 \mu \mathrm{m}$. e) DV - Tissue thickness significantly reduced along the central region of bone defect. HE. Bar: $100 \mu \mathrm{m}$. f) DV - Tissue thickness significantly reduced to the bone edges. HE. Bar: $100 \mu \mathrm{m}$. Microspheres (Mi), granules (Gr), loose conjunctive tissue (LCT), osteoid neoformation ( $\mathrm{ON})$, bone edge (BE), blood capillary (yellow arrows), chronic granulomatous inflammation (red stars), central vein (CV), dura mater region (DM).

The histomorphometric analysis measured the percentage of mineralized linear extension (Table 2). The Kruskal-Wallis test demonstrated statistically significant difference between the 3 groups (MiHA x GrHA $x \mathrm{DV}-p=0.007$ ) and between the experimental and control groups - MiHA $\times$ DV $(p=0.010)$ and GrHA $\times$ DV ( $p=0.046)$. In the groups which the biomaterials were implanted the Kruskal-Wallis test did not demonstrate statistically significant difference- MiHA x GrHA ( $p=1.00)$. 
Table 2 - Histomorphometry of linear extension and mineralized linear extension.

\begin{tabular}{cccc} 
Groups & LE $(\mathbf{m m})$ & MLE $(\mathbf{m m})$ & MLE (\%) \\
& Mean(SD) & Mean(SD) & Mean(SD) \\
\hline MiHA & $7.07(0.30)$ & $1.87(0.69)$ & $26.46(9.78)$ \\
GrHA & $7.28(0.45)$ & $1.46(0.73)$ & $19.73(9,17)$ \\
DV & $8.18(0.11)$ & $0.76(0.09)$ & $9.34(1.05)$ \\
\hline
\end{tabular}

$\mathrm{LE}=$ Linear extension. $\mathrm{MLE}=$ Mineralized Linear Extension. $\mathrm{SD}=$ Standard Deviation.

\section{- Discussion}

The bone repair mechanism is a dynamic, temporal and complex phenomenon that depends on the presence of a threedimensional scaffold and on the manner in which the bone, undifferentiated mesenchymal and endothelial cells interact with each other and with the microenvironment around them. Under the physiological conditions, this event is consolidated by regeneration. On the other hand, when the tissue loss presents critical dimensions, extension and morphology, there is impairment of this mechanism and the tissue repair occurs by fibrosis ${ }^{19,20}$. Under these conditions, bone regeneration becomes limited, as observed in the control group (DV) of our study and in other studies ${ }^{19-22}$. These results validate the simulation of extensive bone loss as it occurs in cases of congenital pathologies, extensive surgical resections, trauma and severe inflammatory diseases. In view of these inhospitable conditions, it is evidenced the need for the use of bone substitutes that make feasible the complete tissue regeneration.

The spatial arrangement of the biomaterials and the neoformed tissues between and around the particles, in the two implanted groupsshowed that the microspheres and granules acted as scaffolds suitable to applications as fillers materials. However, in view of the almost complete reduction of the neoformed interstitium between the granules, it is noted that the spatial arrangement of these biomaterials, similar to the mosaic, interfered in the migration of the cells between the particles during bone repair. These findings were consonant those were evidenced by Ribeiro et al. ${ }^{22}$, who evaluated granules of $\mathrm{HA}$ and alginate in the same biological point.

The evident presence of neoformed blood vessels surrounding the biomaterials demonstrates that the materials evaluated were biocompatible and osteoconductive, independent of the geometric shape, and provided a structure favorable to migration, adhesion and proliferation cellular, the release of growth factors, angiogenesis and tissue neoformation ${ }^{4,12,23}$. Thus, the neoformed osteoid matrix was similarly consolidated in both groups with implantation of biomaterials $(p>0.05)$.

The partial biodegradation of the biomaterials evaluated in this study, most noticeable in the MiHA, demonstrated the influence of alginate on the materials that, when coming into contact with fluids and living tissues, was dissolved by local enzymes and biorreabsorbed. In this way, it induced the gradual release of the inorganic components of the composite, mainly ions of $\mathrm{Ca}$ and $\mathrm{PO}_{4}$, contained in the crystals of HA. These results contradict those observed by Barreto ${ }^{24}$, in which the microspheres of $\mathrm{HA}$ and alginate did not undergo evident biodegradation at the same biological point. This occurred due to the removal of the polymer from the structure of the microspheres during the calcination process. This finding can be attributed, in sum, to the size of the microspheres used 
by Barreto $^{24}$ in relation to those used in our experiment, 400-600 $\mu \mathrm{m}$ and 250-425 $\mu \mathrm{m}$, respectively, because the smaller the particle of the biomaterial, the larger the superficial area of the material exposed to the biological environment. In view of these findings, it is noted that the calcination and sintering processes increase crystallinity, since it favors crystal fusion, aggregation and growth particle, making them resistant to biodegradation ${ }^{24}$. Corroborating with this analysis, in the study by Paula et $a .^{25}$, non calcined microspheres with $400 \mu \mathrm{m}$ showed partial biodegradation with deposition of collagen fibers inside the particles. Conversely, in the study realized by Rossi et al. $^{26}$. the sintered HA microspheres, with the same size as those used in our study, did not present expressive biodegradation, at the same biological point.

One of the technological innovations presented by the biomaterials evaluated in this study, in both geometric shape, was the conception of the HA at nanometric scale. As observed in the MiHA, according to Valenzuela et $a l^{8}$, the nanostructured HA crystals tend to dissolve (biodegrade) faster because of the smaller particle size and the larger surface area exposed to the biological environment.

In our study, the chronic granulomatous inflammation, noted in both groups in which biomaterials were implanted, was compatible with that expected every time a biomaterial is implanted in the living organism ${ }^{27,28}$. This finding proves the biocompatibility of the biomaterials, since there was no rejection by the organism, characterized by acute exacerbated inflammation ${ }^{27,28}$. This potentiality can be attributed, mainly, to the physical-chemical composition of the materials that mimic the inorganic and organic phases of the natural bone tissue, by HAn and alginate, respectively. On the other hand, the more evident chronic granulomatous inflammation in the GrHA, in comparison to the MiHA, reveals that the irregular surface of the granules modulated the cellular response in the interstice between the particles of the biomaterial ${ }^{27,28}$. These findings reveal that the geometry of the biomaterials interferes directly in the tissue response to the presence of the particles ${ }^{5,29}$.

In the study by Ribeiro et $a .^{22}$ the microspheres acted better as filling scaffold and the granules presented superior osteoconductive potential, contrasting our results. It should be emphasized which, in that study, the biomaterials had a diameter of 425$600 \mu \mathrm{m}$; the granules contained $1 \%$ of alginate; and the biomaterials were synthesized by another way. In our experiment, the percentage of alginate used was $1.5 \%$ and diameter of 250 $425 \mu \mathrm{m}$, which may have influenced the tissue response to granules ${ }^{22}$.

Considering that the results of this study are related to the initial phase of the bone repair mechanism (15 days) and can influence, significantly, subsequent cellular events, it becomes pressing the need to develop new studies to observe this response in the long term.

\section{Conclusions}

In the initial phase of bone repair, the geometry of the biomaterials influenced the tissue response to the implantation of HAn and alginate composites. Both biomaterials exhibited neoformation of osteoid matrix, although the microspheres exhibited histological characteristics more favorable to bone regeneration than granules.

\section{- References}

1. O'brien FJ. Biomaterials \& scaffolds for tissue engineering. Mater Today. 2011;14:88-95. doi: 10.1016/S1369-7021(11)70058-X.

2. Chae T, Yang H, Leung V, Ko F, Troczynski T. Novel biomimetic hydroxyapatite/alginate nanocomposite fibrous scaffolds for bone 
tissue regeneration. J Mater Sci Mater Med. 2013;24:1885-94. doi: 10.1007/s10856013-4957-7.

3 Cardoso DA, Ulset AS, Bender J, Jansen JA, Christensen BE, Leeuwenburgh SC. Effects of physical and chemical treatments on the molecular weight and degradation of alginate-hydroxyapatite composites. Macromol Biosci. 2014;14:872-80. doi: 10.1002/mabi.201300415.

4. Santos GG, Vasconcelos LQ, Barbosa Junior AA, Santos SRA, Rossi AM, Miguel $F B$, Rosa FP. Análise da influência de duas faixas granulométricas de microesferas de hidroxiapatita e alginato na fase inicial do reparo ósseo. Rev Ciênc Méd Biol. 2016;15:363-9. doi: 10.9771/cmbio. v15i3.18343.

5. Camargo NHA, Delima SA, Gemelli E. Synthesis and characterization of hydroxyapatite/TiO2n nanocomposites for bone tissue regeneration. Am J Biomed Eng. 2012;2:41-7. doi: 10.5923/j. ajbe.20120202.08.

6. Park $\mathrm{CH}$, Rios HF, Jin $\mathrm{Q}$, Sugai JV, PadialMolina M, Taut AD, Flanagan CL, Hollister SJ; Giannobile, W. V. Tissue engineering boneligament complexes using fiber-guiding scaffolds. Biomaterials. 2012;33:137-45. doi: 10.1016/j.biomaterials.2011.09.057.

7. Guastaldi AC, Aparecida AH. Fosfatos de cálcio de interesse biológico: importância como biomateriais, propriedades e métodos de obtenção de recobrimentos. Quím Nova. 2010;33:1352. doi: 10.1590/S010040422010000600025.

8. Valenzuela F, Covarrubias C, Martínez C, Smith P, Díaz-Dosque $M$, Yazdani-Pedram $M$. Preparation and bioactive properties of novel bone-repair bionanocomposites based on hydroxyapatite and bioactive glass nanoparticles. J Biomed Mater Res B Appl Biomater. 2012;100:1672-82. doi: 10.1002/ jbm.b.32736.

9. Park JH, Lee EJ, Knowles JC, Kim HW. Preparation of in situ hardening composite microcarriers: Calcium phosphate cement combined with alginate for bone regeneration.J BiomaterAppl.2014;28:107984. doi: $10.1177 / 0885328213496486$.

10.Teng S, Shi J, Peng BL, Chen F. The effect of alginate addition on the structure and morphology of hydroxyapatite/ gelatin Nanocomposites. Compos Sci Technol. 2006;66:1532-8. doi: 10.1016/j. compscitech.2005.11.021.

11.Alford $\mathrm{Al}$, Kozloff KM, Hankenson KD. Extracellular matrix networks in bone remodeling. Int J Biochem Cell Biol. 2015;65:20-31. doi: 10.1016/j. biocel.2015.05.008.

12.Venkatesan J, Bhatnagar I, Manivasagan P, Kang KH, Kim SK. Alginate composites for bone tissue engineering: a review. Int J Biol Macromol. 2015;72:269-81. doi: 10.1016/j. ijbiomac.2014.07.008.

13.Logeart-Avramoglou D, Anagnostou F, Bizios $\mathrm{R}$, Petite $\mathrm{H}$. Engineering bone: challenges and obstacles. J Cell Mol Med. 2005;9:72-84. doi: 10.1111/j.15824934.2005.tb00338.x.

14.Pawar SN, Edgar KJ. Alginate derivatization: a review of chemistry, properties and applications. Biomaterials. 2012;33:3279-305. doi: 10.1016/j. biomaterials.2012.01.007.

15. Mavropoulos E, Rocha NCC, Moreira JC, Rossi AM, Soares GA. Characterization of phase evolution during lead immobilization by synthetic hydroxyapatite. Mater Charact. 2004;53:71-8. doi: 10.1016/j. matchar.2004.08.002.

16.Seal BL, Otero TC, Panitch A. Polymeric biomaterials for tissue and organ regeneration. Mater Sci Eng R. 2001;34:147230. doi: 10.1016/S0927-796X(01)00035-3.

17. Markovic M, Fowler BO, Tung J. Preparation and comprehensive characterization of $a$ calcium hydroxyapatite reference material. Res Natl Inst Stand Technol. 2004;109:55368. doi: 10.6028/jres.109.042.

18.Slosarczyk A, Paszkiewicz Z, Paluszkiewicz C. FTIR and XRD evaluation of carbonated dyfroxyapatite powders synthesized by methods. J Mol Struct. 2005;78:657-61. doi: doi.org/10.1016/j.molstruc.2004.11.078.

19. Miguel FB, Cardoso AKMV, Barbosa Júnior AA, Marcantonio Jr E, Goissis G, Rosa FP. Morphological assessment of the behavior of three-dimensional anionic collagen matrices in bone regeneration in rats. J Biomed Mater Res. 2006;78:334-9. doi: 10.1002/jbmb.

20.Cardoso AKMV, Barbosa Junior AA, Miguel $F B$, Marcantonio Junior E, Farina M, Soares GDA, Rosa FP. Histomorphometric analysis 
of tissue responses to bioactive glass implants in critical defects in rat calvaria. Cells Tissues Organs. 2006;184:128-37. doi: 10.1159/000099619.

21.Miguel FB, Barbosa Júnior $A A$, Paula $F L$, Barreto IC, Goissis G, Rosa FP. Regeneration of critical bone defects with anionic collagen matrix as scaffolds. J Mater Sci Mater Med. 2013;24:2567-75. doi: 10.1007/s10856013-4980-8.

22. Ribeiro IIA, Almeida RS, Rocha DN, Prado da Silva $\mathrm{MH}$, Miguel FB, Rosa FP. Biocerâmicas e polímero para a regeneração de defeitos ósseos críticos. Rev Ciênc Méd Biol. 2014;13:298-302. doi: 10.9771/cmbio. v13i3.12934.

23. Liu X, Ma PX. Polymeric scaffolds for bone tissue engineering. Ann Biomed Eng. 2004;32:477-86. PMID: 15095822.

24.Barreto IC. Strontium ranelate utilization in association with biomaterials for bone regeneration (Thesis). Health Science Institute, Universidade Federal da Bahia, 2011.

25.Paula FL, Barreto IC, Rocha-Leao MH, Borojevic R, Rossi AM, Rosa FP, Farina M.
Hydroxyapatite-alginate biocomposite promotes bone mineralization in different length scales in vivo. Front Mater Sci China. 2009;3:145-53. doi: 10.1007/s11706-0090029-9.

26.Rossi AL, Barreto IC, Maciel WQ, Rosa FP, Leao MHMR, Werckmann J, Rossi AM, Borojevic $R$, Farina $M$. Ultrastructure of regenerated bone mineral surrounding hydroxyapatite alginate composite and sintered hydroxyapatite. Bone. 2012;50:30110. doi: 10.1016/j.bone.2011.10.022.

27.Ratner BD, Hoffman AS, Schoen FJ, Lemons JE. Biomaterials science: an introduction to materials in medicine. 2ed. New York: Elsevier Academic Press; 2004.

28.Anderson JM, Rodriguez A, Chang DT. Foreign body reaction to biomaterials. Semin Immunol. 2008;20:86-100. doi: 10.1016/j.smim.2007.11.004.

29.Sponer P, Strnadová M, Urban K. In vivo behaviour of low-temperature calciumdeficient hydroxyapatite: comparison with deproteinised bovine bone. Int Orthop. 2011;35:1553-60. doi: 10.1007/s00264010-1113-6.

\section{Correspondence:}

George Gonçalves dos Santos

Instituto de Ciências da Saúde, Universidade

Federal da Bahia

Avenida Reitor Miguel Calmon s/n, sala 410

40110-902 Salvador - BA Brasil

Tel.: (55) 71)3283-8959

geo.ccs@gmail.com

Received: Oct 16, 2018

Review: Dec 19, 2018

Accepted: Jan 22, 2019
Conflict of interest: none

Financial sources: CAPES, and FAPESB

${ }^{1}$ Research performed at Central Bioterium, Universidade Estadual de Feira de Santana (UEFS), Feira de Santana-BA, and Laboratory of Tissue Bioengineering and Biomaterials (LBTB), Health Sciences Institute, Universidade Federal da Bahia (UFBA), Salvador-BA, Brazil. Part of Master degree thesis, Postgraduate Program in Interactive Processes of Organs and Systems, Health Sciences Institute, UFBA. Tutors: Fabiana Paim Rosa, and Fúlvio Borges Miguel. 